\title{
A simple method for measuring fine-to-ultrafine aerosols using bipolar charge equilibrium
}

\author{
Robert T. Nishida, ${ }^{*}$ Tyler J. Johnson, Joshua S. Hassim, Brian M. Graves, Adam \\ M. Boies, and Simone Hochgreb \\ Department of Engineering, University of Cambridge, Cambridge CB2 1PZ, UK \\ E-mail: rn359@alumni.cam.ac.uk
}

\section{Abstract}

Low-cost methods for measuring airborne microparticles and nanoparticles (aerosols) have remained elusive despite increasing concern of health impacts from ambient, urban and indoor sources. While bipolar ion sources are common in smoke alarms, this work is the first to exploit the mean charge on an aerosol resulting from a bipolar charge equilibrium, and establish experimentally its correlation to properties of the aerosol particle size distribution. The net current produced from this mean particle charge is demonstrated to be linearly proportional to the product of the mean particle diameter and total number concentration $(i \sim N \bar{d})$ for two bipolar ion sources $\left({ }^{85} \mathrm{Kr}\right.$ and $\left.{ }^{241} \mathrm{Am}\right)$. This conclusion is supported by simple equations derived from well-established bipolar charging theory. The theory predicts that the mean charge on the aerosol particles reaches an equilibrium, which, importantly, is independent of the concentration of charging ions. Furthermore, in situ measurements of a roadside aerosol demonstrates the sensing method yields results in good agreement $\left(\mathrm{R}^{2}=0.979\right)$ with existing portable and laboratory-grade aerosol instruments. The simplicity, stability, and cost of the bipolar ion source overcomes challenges of other portable sensors, increasing the feasibility of widespread sensor deployment to monitor ultrafine particle characteristics which are relevant to lung depo- sition and by extension, human health.

Airborne microparticles and nanoparticles (aerosols) from indoor and outdoor air pollution have been strongly linked to a myriad of adverse effects on human health ${ }^{1}$. Multiple large-scale air pollution studies have shown a direct relationship between sub-2.5 $\mu \mathrm{m}$ fine aerosol particulate matter $\left(\mathrm{PM}_{2.5}\right)$ concentrations and allcause mortality $^{2-5}$. Mechanistic studies have indicated that ultrafine particles, a subset of $\mathrm{PM}_{2.5}{ }^{6,7}$ consisting of particles with aerodynamic diameters smaller than $100 \mathrm{~nm}$, may have health impacts beyond those attributed to $\mathrm{PM}_{2.5}$ due to their relatively high number concentration, specific surface area, and potential for deeper penetration into human lungs ${ }^{8}$. Epidemiological evidence remains limited due to a lack of sensors appropriate for monitoring local concentrations of fine-to-ultrafine particles $^{6}$, particularly those tailored to the concerns caused by the surface area and number concentrations of particles between $10 \mathrm{~nm}$ to 1 $\mu \mathrm{m}$.

Existing methods for detection of ultrafine particles require full benchtop systems and/or are prohibitively expensive for large scale de-

Keywords: Air Pollution Sensor, Particulate Matter, Aerosols, Low-cost Sensing, Bipolar Charge Distribution, Lung-deposited Surface Area 
ployment $^{9}$. Networks of low-cost, distributable sensors for monitoring ultrafine particles in urban areas or transport centres could be used to carry out source attribution ${ }^{10,11}$, inform policy $^{12}$ and support epidemiological studies ${ }^{6}$. Other applications of such sensors include workplace hazard and exposure identification ${ }^{13}$, and engine emissions monitoring ${ }^{14}$.

In this work, a new method for measuring aerosols with particle diameters between $44 \mathrm{~nm}$ and $1.05 \mu \mathrm{m}$ is experimentally demonstrated, with widely-accepted charging theory ${ }^{15}$ predicting measurements below $10 \mathrm{~nm}$. This method has the potential to be implemented at sufficiently low cost for widespread deployment and leverages a common practice in aerosol science of producing gaseous ions of both polarities to charge particles to a stable, equilibrium state. The present proof-of-concept device distinctively uses the mean charge from bipolar charging for quantitative aerosol measurements, and is described and quantitatively demonstrated both in a laboratory setting using a controlled aerosol source and in situ by sampling a roadside aerosol. These validation results are also supported by well-established theory on aerosol charging.

\section{Bipolar charging theory}

Bipolar diffusion charging involves ionizing gas molecules into both positively and negatively charged ions using alpha or beta radioactive decay $^{16-18}$, X-ray ionisation ${ }^{7,19}$ or other methods $^{20-23}$. These ions subsequently transfer charge via collisions with particles by means of diffusive and electrostatic forces, resulting in a particle charge distribution consisting of positive, negative and neutral particles ${ }^{15,24}$. Assuming that sufficient bipolar ion concentrations are available ${ }^{18,25}$, a stationary charge state distribution is established, henceforth referred to as an equilibrium ${ }^{15}$. At this equilibrium state, the rate of positive charge transfer to particles with $q$ charges to reach $q+1$ charges is equal to the reverse rate of negative charge transfer to particles with $q+1$ charges to reach $q$ charges $^{24}$. Furthermore, existing charging theory shows that under these conditions, the frac- tion of particles at each charge state is only a function of particle size, and, importantly, independent of both the particle and ion concentrations ${ }^{18}$. This is in contrast to unipolar diffusion charging used in portable sensors for particles $^{26-29}$, where the charge fractions depend on the ion concentration $\left(n_{i}\right)$ and the diffusion residence time $(t)^{30-32}$, which are functions of the efficacy of the ion source and design of the charger ${ }^{33}$. Therefore, the bipolar charging method offers a significant advantage relative to other charging methods such as unipolar diffusion, because one can unambiguously predict the charge distribution and mean charge as a function of particle diameter for a given gas mixture and its conditions.

At bipolar charge equilibrium, the fraction of total particles $\left(f_{q}\right)$ at each charge state $(q)$ as a function of particle diameter greater than $50 \mathrm{~nm}^{15}$ is estimated by Gunn and Woessner ${ }^{34}$. Therefore, the sensing method and theory explicitly considers multiply-charged particles which act to increase the measurement signal. The mean charge per particle $\left(\bar{q}_{d}\right)$ for a given particle diameter $(d)$ is given as the sum:

$$
\bar{q}_{d}=\sum_{q} q f_{q}(d)
$$

When the aerosol is carried by a gas flow, the net flux of charge yields a corresponding electrical current as a function of diameter $\left(i_{d}\right)$ as:

$$
i_{d}=Q e N_{d} \bar{q}_{d}
$$

where $Q$ is the volumetric flow rate of the gas containing the charged aerosol, $e$ is the elementary charge $\left(1.6 \times 10^{-19} \mathrm{C}\right)$ and $N_{d}$ is the number concentration of particles with diameter $d$.

The summation over the discrete charge states of Eq. 1 requires numerical calculations. To simplify and elucidate these relations, Eq. 1 may be approximated by an integral and solved analytically as derived in Section S-1 of the Supporting Information (SI) as follows:

$$
\bar{q}_{d}=\frac{i_{d}}{N_{d} Q e}=\frac{2 \pi \varepsilon_{0} k T}{e^{2}} \ln \left(\frac{Z_{+}}{Z_{-}}\right) d
$$

for a given absolute temperature $(T)$, positive to negative ion mobility ratio $\left(Z_{+} / Z_{-}\right)$, and the 
a)

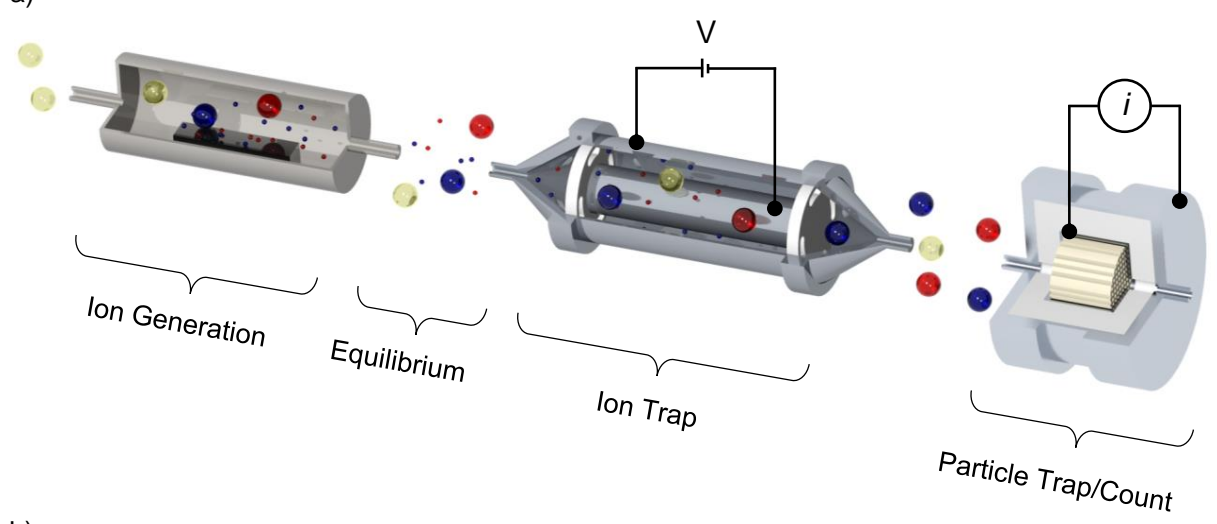

b)

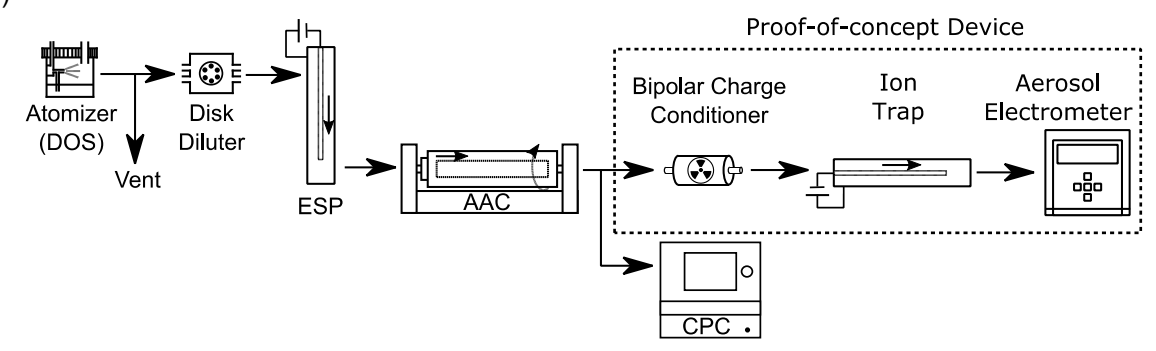

Figure 1: (a) The method is described by four key components: (1) ion generation via a bipolar charge conditioner in which (2) an equilibrium of particle charge states is reached, (3) an ion trap and (4) a Faraday cup electrometer which measures the net electrical current from the sample flow of charged aerosol trapped in a filter. (b) Schematic of experimental apparatus for evaluating the operating method using controlled particle size and concentration.

constants of electron charge $(e)$, vacuum permittivity $\left(\varepsilon_{0}\right)$ and Boltzmann's constant $(k)$. This solution has a form previously derived in Clement and Harrison ${ }^{35}$ for the mean charge of an aerosol at bipolar equilibrium.

Equation 3 indicates that the mean charge per particle $\left(\bar{q}_{d}\right)$ and corresponding net current $\left(i_{d}\right)$ for a given particle diameter $(d)$ is a simple linear function of particle diameter, the gas temperature $(T)$, and the natural log of the ratio of positive to negative ion mobilities $\left(Z_{+} / Z_{-}\right)$. For a polydisperse distribution, the resulting current $(i)$ is proportional to the product of the total particle number concentration $(N)$ and the first moment average diameter $(\bar{d}$; or arithmetic mean diameter) of the particle size distribution, $i \sim N \bar{d}=\int N_{d} d \mathrm{~d} d$ (see SI Equations S-8 to S-10 and Nishida et al. ${ }^{36}$ for further details). Importantly, at equilibrium, this relation is independent of the ion concentrations and residence time, effectively removing those design parameters. Furthermore, the first moment of a particle size distribution is equivalent to the lung-deposited surface area (LDSA) of ultrafine particles or the fraction of airborne particle surface area concentration that likely deposits in a human lung ${ }^{37}$. The definition of LDSA is limited to the range of approximately $20-400 \mathrm{~nm}$ by the lung deposition curve ${ }^{38}$, therefore, the 'first moment of a particle size distribution' is defined and measured in this work.

\section{Methods}

The working principle includes four main components as shown in Figure 1a. An aerosol is sampled continuously and charged in the ion generation module, which uses a bipolar source to produce sufficiently high ion concentrations for the particle charges to reach equilibrium ${ }^{18}$. An ion trap then removes the excess gaseous ions by applying a small electrical potential difference $(<10 \mathrm{~V})$ between two electrodes to generate a weak electrostatic field across the sample flow. The electrical mobility of the ions is over 100 times greater than that of the charged 
particles in the size range of interest $(10 \mathrm{~nm}$ $<d<1 \mu \mathrm{m})^{7}$, so the ions can be trapped without significant particle loss ${ }^{39}$. Finally, a Faraday cup electrometer (FCE) traps all of the particles (including the neutral fraction) using a high-efficiency particulate air (HEPA) filter. The flux of charged particles into the particle trap induces an image current on the Faraday cup, which is measured by an ammeter.

Laboratory validation measurements were conducted using the setup shown in Figure $1 \mathrm{~b}$ to measure the current generated from the flow of charged particles $\left(i_{d}\right)$ with a known particle number concentration $\left(N_{d}\right)$ and monodisperse diameter $(d)$. Spherical, bis(2-ethylhexyl) sebacate (DOS) particles were generated and diluted to provide a range of particle number concentrations (dilution ratios between 10 and 150). A custom-built electrostatic precipitator removed any particles charged during atomization or dilution. The diluted, neutral aerosol sample was then classified by an aerodynamic aerosol classifier (AAC) to generate an aerodynamically monodispersed source ${ }^{40}$. Due to the particles being spherical, it was possible to calculate the equivalent particle geometric diameter $(d)$ for each AAC setpoint, which was also equivalent to the particle mobility diameter, a parameter commonly used by others to validate bipolar and unipolar diffusion charging theory ${ }^{41,42}$. The neutrally charged, monodispersed particles were sampled by a condensation particle counter (CPC) to measure the particle number concentration $(N)$ in parallel with the proof-of-concept measurement device. The disk diluter and AAC controlled the particle number concentration and particle size, respectively.

The proof-of-concept device consisted of a bipolar charge conditioner followed by an ion trap and aerosol electrometer as depicted in Figure 1b. The ion source for the bipolar charge conditioner was either ${ }^{85} \mathrm{Kr}$ (beta decay, 10.76 year half life) with $10 \mathrm{mCi} / 370 \mathrm{MBq}$ activity or three units of ${ }^{241} \mathrm{Am}$ (alpha decay, 432.2 years half-life) with a combined activity of less than $3.0 \mu \mathrm{Ci} / 111 \mathrm{kBq}$. These ${ }^{241} \mathrm{Am}$ units, each with less than $1 \mu \mathrm{Ci}$ activity, are commonly found in ionisation-type smoke alarms (which are the most common smoke alarm type in U.S. homes ${ }^{43}$ ), and conform to national regulatory requirements for radioactive materials which do not require special handling procedures for consumers ${ }^{44}$. That quantity of ${ }^{241} \mathrm{Am}$ typically costs less than $\$ 0.01$ per device at $\$ 1.50 / \mathrm{mg}^{45}$, orders of magnitude less expensive than the components required for a corona discharge ion source, commonly used for unipolar charging. After charging the particles, an electrostatic precipitator with a low voltage $(0.07 \mathrm{~V})$ was used as an ion trap. Finally, the aerosol electrometer, which includes a Faraday Cup Electrometer (FCE), measured the net current $(i)$ from the charged particles while controlling the flow rate $(Q)$. The specifications for the electrometry ( $<1$ fA RMS noise, 1 s averaging time) are commonly achieved in aerosol measurements ${ }^{46,47}$ including in portable, unipolar charging-based sensors for particles ${ }^{26-29}$.

The mean charge per particle at a given particle diameter $\left(\bar{q}_{d}\right)$ is determined based on the electrical current $\left(i_{d}\right)$ measured by the aerosol electrometer operating with a set flow rate $(Q=$ $0.3 \mathrm{std} \mathrm{L} \mathrm{min}^{-1}$ ), and is compared against the one predicted by theory using Eq. 3 based on the total particle number concentration $(N)$ measured by the CPC and the particle diameter $(d)$ selected by the AAC.

In a separate experiment, in situ measurements were conducted using the proof-ofconcept device to measure ambient aerosols on a roadside located adjacent to the south side of the Department of Engineering in Cambridge, UK. In parallel to the proof-of-concept device, a CPC measured the total number concentration, a Naneos Partector measured Lung Deposited Surface Area (LDSA) ${ }^{28,48}$, and a Scanning Mobility Particle Sizer measured the particle mobility size distribution. The $1 \mathrm{~Hz}$ signal from each device was averaged over 1 minute except for the SMPS which had a sampling period of 2 minutes. Further details of the methods utilized in the laboratory validation experiments using a controlled aerosol source and in situ demonstration by sampling a roadside aerosol are outlined in Sections S-2.1 and S-2.2 of the SI, respectively. 


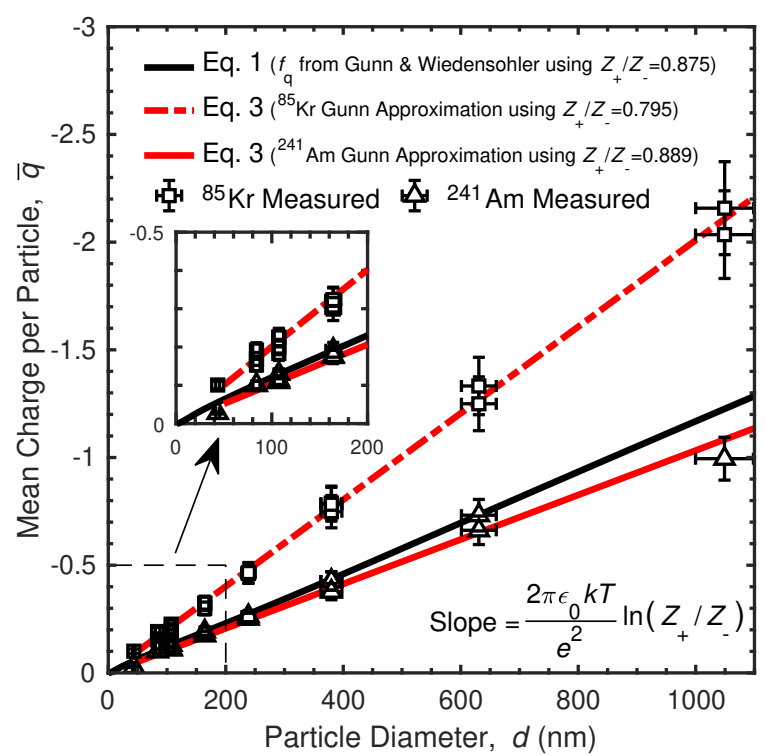

(a)

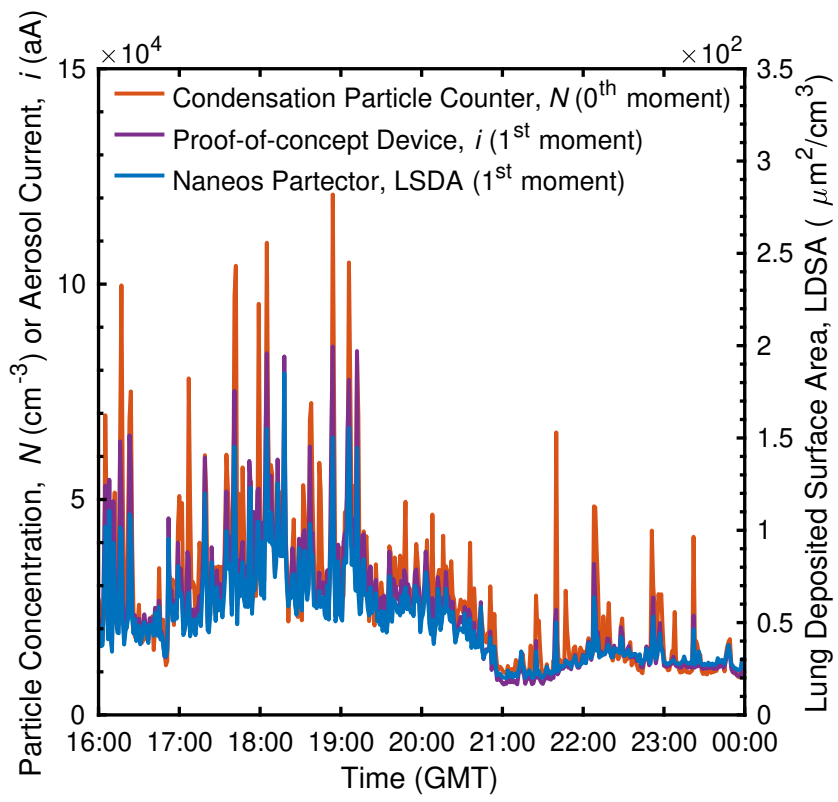

(b)

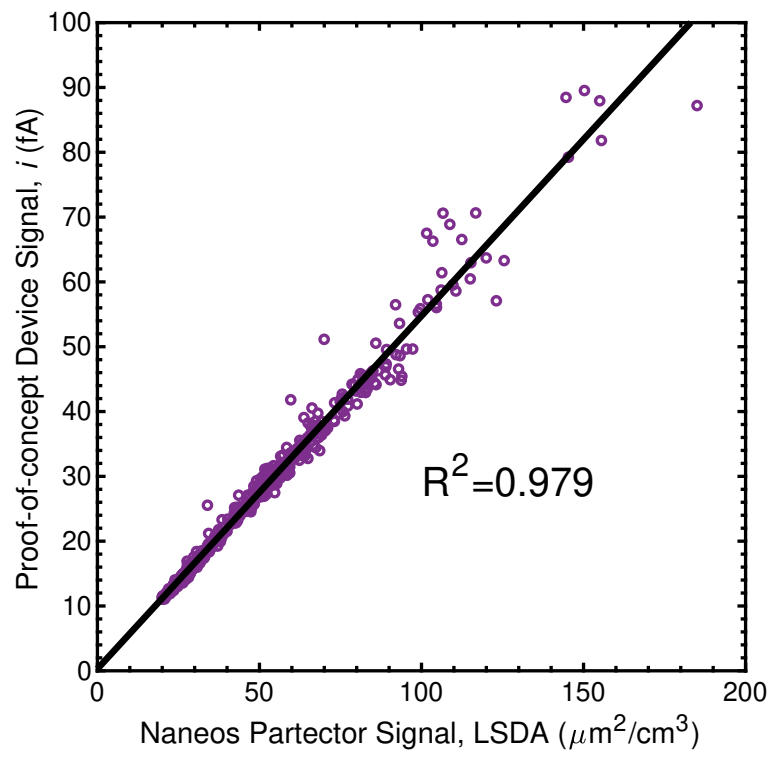

(c)

Figure 2: (a) Mean charge per particle $\left(\bar{q}_{d}\right)$ as a function of particle diameter $(d)$ for experimental results and theory (Eq. 3 or Eq. 1 for ISO Standard conditions ${ }^{18}$ ). (b) Roadside aerosol measurements comparing currents measured with the proof-of-concept device (equivalent to the first moment of a particle size distribution) against LDSA (also equivalent to the first moment of a particle size distribution) measured with a Naneos Partector, and particle number concentration ( $N$, or equivalent to the zeroth moment of a particle size distribution) measured with a CPC. (c) Correlation between current measured with the proof-of-concept device and the LDSA measured with a Naneos Partector (linear regression fit, $\mathrm{R}^{2}=0.979$ ).

\section{Results and Discussion}

Laboratory measurements of mean charge per particle $\left(\bar{q}_{d}\right)$ as a function of particle diam- eter using either the ${ }^{85} \mathrm{Kr}$ or ${ }^{241} \mathrm{Am}$ bipolar ion source are shown in comparison to the- 
ory in Figure 2a. The total particle number concentrations tested ranged from $3.3 \times 10^{3}$ to $1.3 \times 10^{5} \mathrm{~cm}^{-3}$ and $6.3 \times 10^{3}$ to $7.2 \times 10^{4} \mathrm{~cm}^{-3}$ for ${ }^{85} \mathrm{Kr}$ and ${ }^{241} \mathrm{Am}$, respectively, and the monodispersed particle diameter was varied from $44 \mathrm{~nm}$ to $1.05 \mu \mathrm{m}$. The horizontal and vertical errors bars depicted in Figure 2a illustrate the $4.7 \%$ and $10 \%$ accuracy of the $\mathrm{AAC}^{49}$ and $\mathrm{CPC}^{50}$, respectively. Within the particle size range considered, the experimental data demonstrates that the measured aerosol current $\left(i_{d}\right)$ is linear with respect to particle diameter $\left(i_{d} \sim d\right)$ within the experimental uncertainty, and that the mean charge per particle $\left(\bar{q}_{d}\right)$ is independent of the particle number concentration $\left(N_{d}\right)$ for diameter $d$ as expected by theory. The consistency of mean charge per particle with varying concentrations for a given particle diameter indicates that charge equilibrium was effectively reached for those data points. However, in other cases, charge equilibrium may not be reached due to flow effects, limited particle residence time and/or insufficient ion concentrations ${ }^{18,25,51}$.

The dashed and solid red lines were calculated using the integral approximation (valid for particles larger than approximately $50 \mathrm{~nm}^{15}$ ) to analytically estimate the mean charge per particle (see Eq. 3 and the bottom right corner of Figure 2a). Since the analytical equation for the lines contains only absolute temperature $(T)$, four constants and the ratio of ion mobilities $\left(Z_{+} / Z_{-}\right)$, the latter was used as a fitting parameter for the two different charge conditioners used. The ion mobility ratios $\left(Z_{+} / Z_{-}\right)$ were 0.795 and 0.889 for the ${ }^{85} \mathrm{Kr}$ and ${ }^{241} \mathrm{Am}$ sources, respectively, determined from regression fits $\left(\mathrm{R}^{2}\right.$ values of 0.998 and 0.984 , respectively) of Eq. 3 to the experimental data. The ion mobility ratios obtained are near the average ratio of 0.8 determined by Tigges et al. ${ }^{51}$ for a range of bipolar charge conditioners studied over the past 50 years by others.

The difference between the ratios of ion mobilities is likely from the two different ion sources ${ }^{51},{ }^{85} \mathrm{Kr}$ (beta decay) and ${ }^{241} \mathrm{Am}$ (alphadecay). This inference is supported by Figure S1 of Leppä et al. ${ }^{52}$ which shows significant differences in ion mobilities between ${ }^{85} \mathrm{Kr}$ and ${ }^{241} \mathrm{Am}$ ion sources. Bipolar charge distributions and therefore measurements of this device may be affected by variability in ion mobilities. However, these effects are also present in other electrostatic aerosol instruments, such as the SMPS which is used as a particle measurement standard (ISO 15900) ${ }^{18,52-54}$ and other charging-based aerosol instruments ${ }^{55,56}$.

The solid black line in Figure 2a was calculated using Eq. 1 for the equilibrium charge distribution predicted by Wiedensohler ${ }^{15}$ and Gunn and Woessner ${ }^{34}$ as outlined in ISO Standard 15900 which explicitly uses the ion mobility ratio $\left(Z_{+} / Z_{-}\right)$of $0.875^{18}$. The validity of this method has been confirmed by more recent studies ${ }^{42,57}$ using the ion mobility ratio $\left(Z_{+} / Z_{-}=0.875\right)$ originally measured from a ${ }^{210} \mathrm{Po}$ alpha emitter ${ }^{58}$. This line is approximately linear down to $10 \mathrm{~nm}$ supporting the applicability of this method to characterize sub-50 nm particles; however, theory and experimental validation for linearity in this size range requires further investigation.

In situ, roadside aerosols may in general contain heterogeneous mixtures of different sizes, shapes, and chemical constituents of particles. The mobility diameter $\left(d_{\mathrm{m}}\right)$ is often used to approximate the particle diameter $(d)$ for diffusion charging of arbitrary shaped particles ${ }^{41,42}$ such as those expected in the roadside aerosol and is done so in the following analysis.

Figure 2b compares ambient aerosol measurements from the roadside using the proofof-concept device (electrical current, $i$ ), CPC (particle number concentration, $N$ ) and $\mathrm{Na}$ neos Partector (LDSA) from rush hour to midnight on a Friday. Over this time range, Figure $2 \mathrm{~b}$ shows the agreement between the proofof-concept device and Naneos Partector is excellent $\left(\mathrm{R}^{2}=0.979\right.$ as shown in Figure $\left.2 \mathrm{c}\right)$ as the former measures the first moment of the ambient, polydispersed particle size distribution (i.e. $i \sim N \overline{d^{x}}$ where $x=1$ ) and the latter measures a close approximation to that measurement (i.e. $i \sim N \overline{d^{x}}$ where $x \approx 1.1$ ), presented as LDSA ${ }^{37}$. Both the proof-of-concept device and Naneos Partector are compared with the CPC since it is a widely used reference instrument. However, the CPC measures the zeroth moment of 
the ambient, polydispersed particle size distribution (i.e. $N \overline{d^{x}}$ where $x=0$ ). Therefore a direct correlation between the $\mathrm{CPC}$ and proof-ofconcept device provides limited value and was not completed. Over the time range shown, the mean charge per particle* was $\bar{q}=0.11$, which, based on Eq. S-10 applied for a polydisperse distribution (see SI Equations S-8 to S-10 for further details) corresponds to an arithmetic mean particle diameter $(\bar{d})$ of $64 \mathrm{~nm}^{\dagger}$. This agrees well (8.8\% difference) with the arithmetic mean of the mobility diameter distribution $\left(\bar{d}_{\mathrm{m}}\right)$ of $70.2 \mathrm{~nm}$ measured by the SMPS over the same time range. These signal and size agreements demonstrate that the ion mobility ratio found from in-lab experiments (Figure 2a) can be used as a one-parameter calibration to yield quantitative accuracy in comparison with widely accepted reference instruments.

The signal and size agreements with the reference instruments (CPC, Naneos Partector and SMPS) demonstrate that the proof-of-concept device has quantitative accuracy when used in situ in a real-world setting for a heterogeneous aerosol mixture. Roadside aerosols generally have a range of chemical compositions and morphologies of particles; however, both bipolar and unipolar diffusion charging methods are relatively insensitive to these properties compared to other low-cost methods ${ }^{59-61}$, thereby improving measurements.

\section{Conclusions}

Bipolar charging was used to bring an aerosol stream to an equilibrium charge state. For a given flow rate $(Q)$, the net aerosol current produced by this charge state was shown to be linearly proportional to the product of the particle number concentration and mean particle diameter $(i \sim N \bar{d})$. This conclusion is supported by a simple analytical model derived using well-

*Determined using Eq. S-10 with the current and number concentration measured by the proof-of-concept device and $\mathrm{CPC}$, respectively, and then averaging the mean charge over the time range considered.

${ }^{\dagger}$ Determined using an ion mobility ratio of $Z_{+} / Z_{-}=0.795$ as determined from the laboratory measurements of the ${ }^{85} \mathrm{Kr}$ charge conditioner. established theory on bipolar charging. The analytical equation further predicts that the net charge per particle is linearly proportional to the natural $\log$ of the positive to negative ion mobility ratio produced by the bipolar charge conditioner, as well as the gas temperature and four constants. Importantly, the net charge is independent of charging time and the ion concentrations, providing more reliable charging than typical implementations of unipolar charging. A proof-of-concept device experimentally confirmed theoretical predictions for a wide range of particle mobility diameters (44 to $1.05 \mu \mathrm{m})$ and number concentrations $\left(3.3 \times 10^{3}\right.$ to $1.3 \times 10^{5} \mathrm{~cm}^{-3}$ ) of spherical particles, with theory predicting a continued linear correlation down to $10 \mathrm{~nm}$ particles. The principle was also demonstrated using an ${ }^{241} \mathrm{Am}$ ion source, which is widely used in ionization-type smoke alarms. This provides opportunities for optimization of a low-cost, quantitative sensor for fine-to-ultrafine particles, since the ion source is orders of magnitude cheaper and and more compact than a corona discharge ion source. In situ, roadside measurements confirmed quantitative accuracy of the proposed method by comparison against reference, commercial instruments. Quantitative agreement with a Naneos Partector was $\mathrm{R}^{2}=0.979$ over eight hours during and after rush hour traffic. The proposed device measures the first-moment of a particle mobility size distribution which may be expressed as a lung-deposited surface area (LDSA) of ultrafine particles. The simplicity, stability, and cost advantages of this method could overcome the challenges of existing devices, enabling widespread deployment to directly measure particle concentration averages for aerosols which are relevant to lung deposition and by extension, human health.

Acknowledgement The authors acknowledge Dr. Molly Haugen for assistance in gathering experimental data as well as Dr. Marc Stettler of Imperial College London for loaning the Naneos Partector. The authors thank Mario Schriefl for helpful discussions. The authors thank Cambustion Ltd. for providing the disk diluter and ESP. Funding for RTN was pro- 
vided by Alphasense Ltd. and Natural Sciences and Engineering Research Council of Canada (NSERC). TJJ acknowledges funding from the Rt. Hon. Sir Winston S. Churchill Society of Edmonton and BMG acknowledges funding from NSERC, the Rt. Hon. Sir Winston S. Churchill Society of Edmonton, and the Cambridge Trust.

\section{Supporting Information Avail- able}

The following files are available free of charge.

- SI.pdf: Analytical explanation of net bipolar charge; Detailed description of experimental setups and procedures for laboratory and roadside measurement;

\section{References}

(1) World Health Organization, Ambient air pollution: A global assessment of exposure and burden of disease. 2016.

(2) Beelen, R.; Raaschou-Nielsen, O.; Stafoggia, M.; Andersen, Z. J.; Weinmayr, G.; Hoffmann, B.; Wolf, K.; Samoli, E.; Fischer, P.; Nieuwenhuijsen, M.; et al., Effects of long-term exposure to air pollution on natural-cause mortality: an analysis of 22 European cohorts within the multicentre ESCAPE project. The Lancet 2014, 383, 785-795.

(3) Lelieveld, J.; Evans, J. S.; Fnais, M.; Giannadaki, D.; Pozzer, A. The contribution of outdoor air pollution sources to premature mortality on a global scale. Nature 2015, 525, 367-371.

(4) Apte, J. S.; Brauer, M.; Cohen, A. J.; Ezzati, M.; Pope, C. A. Ambient PM2.5 Reduces Global and Regional Life Expectancy. Environmental Science 83 Technology Letters 2018, 5, 546-551.

(5) Cohen, A. J.; Brauer, M.; Burnett, R.; Anderson, H. R.; Frostad, J.; Estep, K.;
Balakrishnan, K.; Brunekreef, B.; Dandona, L.; Dandona, R.; et al., Estimates and 25-year trends of the global burden of disease attributable to ambient air pollution: an analysis of data from the Global Burden of Diseases Study 2015. The Lancet 2017, 389, 1907-1918.

(6) U.S. EPA, Integrated Science Assessment for Particulate Matter. 2009.

(7) Kulkarni, P.; Baron, P. A.; Willeke, K. Aerosol measurement: principles, techniques, and applications; John Wiley \& Sons, 2011.

(8) Oberdörster, G.; Oberdörster, E.; Oberdörster, J. Nanotoxicology: an emerging discipline evolving from studies of ultrafine particles. Environmental Health Perspectives 2005, 113, 823-839.

(9) Bau, S.; Zimmermann, B.; Payet, R.; Witschger, O. A laboratory study of the performance of the handheld diffusion size classifier (DiSCmini) for various aerosols in the 15-400 nm range. Environmental Science: Processes \& Impacts 2015, 17, 261-269.

(10) Mead, M. I.; Popoola, O. A. M.; Stewart, G.; Landshoff, P.; Calleja, M.; Hayes, M.; Baldoví, J. J.; McLeod, M. W.; Hodgson, T. F.; Dicks, J.; Lewis, A. C.; Cohen, J.; Baron, R.; Saffell, J.; Jones, R. L. The use of electrochemical sensors for monitoring urban air quality in low-cost, high-density networks. Atmospheric Environment 2013, 70, 186-203.

(11) Ott, W. R.; Siegmann, H. C. Using multiple continuous fine particle monitors to characterize tobacco, incense, candle, cooking, wood burning, and vehicular sources in indoor, outdoor, and in-transit settings. Atmospheric Environment 2006, 40, 821-843.

(12) Kumar, P.; Morawska, L.; Martani, C.; Biskos, G.; Neophytou, M.; Di Sabatino, S.; Bell, M.; Norford, L.; 
Britter, R. The rise of low-cost sensing for managing air pollution in cities. Environment International 2015, 75, 199-205.

(13) Brouwer, D. H.; Gijsbers, J. H.; Lurvink, M. W. Personal exposure to ultrafine particles in the workplace: Exploring sampling techniques and strategies. Annals of Occupational Hygiene 2004, 48, 439-453.

(14) Kittelson, D. B.; Watts, W. F.; Savstrom, J. C.; Johnson, J. P. Influence of a catalytic stripper on the response of real time aerosol instruments to diesel exhaust aerosol. Journal of Aerosol Science 2005, 36, 1089-1107.

(15) Wiedensohler, A. An approximation of the bipolar charge distribution for particles in the submicron size range. Journal of Aerosol Science 1988, 19, 387-389.

(16) Cooper, D. W.; Reist, P. C. Neutralizing charged aerosols with radioactive sources. Journal of Colloid and Interface Science 1973, 45, $17-26$.

(17) Liu, B. Y.; Pui, D. Y. Electrical neutralization of aerosols. Journal of Aerosol Science 1974, 5, 465 - 472 .

(18) ISO, BS ISO 15900: 2009 (E) Determination of particle size distributiondifferential electrical mobility analysis for aerosol particles. 2009.

(19) Shimada, M.; Han, B.; Okuyama, K.; Otani, Y. Bipolar Charging of Aerosol Nanoparticles by a Soft X-ray Photoionizer. Journal of Chemical Engineering Japan 2002, 35, 786-793.

(20) Adachi, M.; Pui, D. Y. H.; Liu, B. Y. H. Aerosol Charge Neutralization by a Corona Ionizer. Aerosol Science and Technology 1993, 18, 48-58.

(21) Stommel, Y.; Riebel, U. A new corona discharge-based aerosol charger for submicron particles with low initial charge.
Journal of Aerosol Science 2004, 35, 1051 -1069 .

(22) Han, B.; Hudda, N.; Ning, Z.; Kim, H.J.; Kim, Y.-J.; Sioutas, C. A novel bipolar charger for submicron aerosol particles using carbon fiber ionizers. Journal of Aerosol Science 2009, 40, 285 - 294.

(23) Kwon, S.; Sakurai, H.; Seto, T.; Kim, Y. Charge neutralization of submicron aerosols using surface-discharge microplasma. Journal of Aerosol Science 2006, 37, $483-499$.

(24) Fuchs, N. A. On the stationary charge distribution on aerosol particles in a bipolar ionic atmosphere. Geofisica Pura E Applicata 1963, 56, 185-193.

(25) de La Verpilliere, J.; Swanson, J. J.; Boies, A. M. Unsteady bipolar diffusion charging in aerosol neutralisers: A nondimensional approach to predict charge distribution equilibrium behaviour. Journal of Aerosol Science 2015, 86, 55-68.

(26) Marra, J.; Voetz, M.; Kiesling, H.-J. Monitor for detecting and assessing exposure to airborne nanoparticles. Journal of Nanoparticle Research 2010, 12, 21-37.

(27) Jung, H.; Kittelson, D. B. Characterization of aerosol surface instruments in transition regime. Aerosol Science and Technology 2005, 39, 902-911.

(28) Fierz, M.; Meier, D.; Steigmeier, P.; Burtscher, H. Aerosol measurement by induced currents. Aerosol Science and Technology 2014, 48, 350-357.

(29) Fierz, M.; Houle, C.; Steigmeier, P.; Burtscher, H. Design, calibration, and field performance of a miniature diffusion size classifier. Aerosol Science and Technology 2011, 45, 1-10.

(30) Biskos, G.; Reavell, K.; Collings, N. Unipolar diffusion charging of aerosol particles in the transition regime. Journal of Aerosol Science 2005, 36, 247-265. 
(31) Büscher, P.; Schmidt-Ott, A.; Wiedensohler, A. Performance of a unipolar "square wave" diffusion charger with variable nt-product. Journal of Aerosol Science 1994, 25, 651-663.

(32) White, H. J. Particle charging in electrostatic precipitation. Transactions of the American Institute of Electrical Engineers 1951, 70, 1186-1191.

(33) Flagan, R. C. Differential mobility analysis of aerosols: a tutorial. KONA Powder and Particle Journal 2008, 26, 254-268.

(34) Gunn, R.; Woessner, R. Measurements of the systematic electrification of aerosols. Journal of Colloid Science 1956, 11, 254259.

(35) Clement, C.; Harrison, R. The charging of radioactive aerosols. Journal of aerosol science 1992, 23, 481-504.

(36) Nishida, R. T.; Yamasaki, N.; Schriefl, M. A.; Boies, A.; Hochgreb, S. Modelling the effect of aerosol polydispersity on unipolar charging and measurement in low-cost sensors. Journal of Aerosol Science 2019, 130, 10-21.

(37) Fissan, H.; Neumann, S.; Trampe, A.; Pui, D.; Shin, W. Nanotechnology and Occupational Health; Springer, 2006; pp 5359 .

(38) ICRP, Human Respiratory Tract Model for Radiological Protection; Ann. ICRP, 1994; Vol. 24 (1-3).

(39) Nishida, R.; Boies, A. M.; Hochgreb, S. Modelling of direct ultraviolet photoionization and charge recombination of aerosol nanoparticles in continuous flow. Journal of Applied Physics 2017, 121, 023104, 1-13.

(40) Tavakoli, F.; Symonds, J. P. R.; Olfert, J. S. Generation of a monodisperse size-classified aerosol independent of particle charge. Aerosol Science and Technology 2014, 48, i-iv.
(41) Gopalakrishnan, R.; Thajudeen, T.; Ouyang, H.; Hogan Jr, C. J. The unipolar diffusion charging of arbitrary shaped aerosol particles. Journal of Aerosol Science 2013, 64, 60-80.

(42) Gopalakrishnan, R.; McMurry, P. H.; Hogan Jr, C. J. The bipolar diffusion charging of nanoparticles: A review and development of approaches for nonspherical particles. Aerosol Science and Technology 2015, 49, 1181-1194.

(43) Ahrens, M. Smoke alarms in US home fires; National Fire Protection Association, Fire Analysis and Research Division, 2014

(44) United States Nuclear Regulatory Commission, NRC Regulations Title 10, Code of Federal Regulations, Part 30.12. 2012; https://www.nrc.gov/ reading-rm/doc-collections/cfr/ part030/part030-0015.html.

(45) Canadian Nuclear Society, Smoke detectors and americium-241 factsheet. 2008; https://cns-snc.ca/media/pdf_ doc/ecc/smoke_am241.pdf.

(46) Yang, Y.; Yu, T.; Zhang, J.; Wang, J.; Wang, W.; Gui, H.; Liu, J. On the performance of an aerosol electrometer with enhanced detection limit. Sensors 2018, 18, 3889, 1-13.

(47) Intra, P.; Tippayawong, N. Development and evaluation of a Faraday cup electrometer for measuring and sampling atmospheric ions and charged aerosols. Particulate Science and Technology 2015, 33, 257-263.

(48) Todea, A. M.; Beckmann, S.; Kaminski, H.; Asbach, C. Accuracy of electrical aerosol sensors measuring lung deposited surface area concentrations. Journal of Aerosol Science 2015, 89, 96-109.

(49) Johnson, T. J.; Irwin, M.; Symonds, J. P.; Olfert, J. S.; Boies, A. M. Agreement Between Different Aerosol Classifiers Using 
Spherical Particles; Cambridge Particle Meeting: Cambridge, UK, June 15, 2018.

(50) TSI Inc., Model 3776 Ultrafine Condensation Particle Counter: Operation and Service Manual, Revision B; TSI, 2006.

(51) Tigges, L.; Jain, A.; Schmid, H.-J. On the bipolar charge distribution used for mobility particle sizing: Theoretical considerations. Journal of Aerosol Science 2015, 88, 119-134.

(52) Leppä, J.; Mui, W.; Grantz, A. M.; Flagan, R. C. Charge distribution uncertainty in differential mobility analysis of aerosols. Aerosol Science and Technology 2017, 51, 1168-1189.

(53) Chen, X.; Jiang, J. Retrieving the ion mobility ratio and aerosol charge fractions for a neutralizer in real-world applications. Aerosol Science and Technology 2018, 52, $1145-1155$.

(54) Wiedensohler, A.; Birmili, W.; Nowak, A.; Sonntag, A.; Weinhold, K.; Merkel, M.; Wehner, B.; Tuch, T.; Pfeifer, S.; Fiebig, M.; et al., Mobility particle size spectrometers: harmonization of technical standards and data structure to facilitate high quality long-term observations of atmospheric particle number size distributions. Atmospheric Measurement Techniques 2012, 5, 657-685.

(55) Biskos, G.; Reavell, K.; Collings, N. Description and theoretical analysis of a differential mobility spectrometer. Aerosol Science and Technology 2005, 39, 527541.

(56) Marjamäki, M.; Keskinen, J.; Chen, D.R.; Pui, D. Y. H. Performance evaluation of the electrical low-pressure impactor (ELPI). Journal of Aerosol Science 2000, 31, 249-261.

(57) Gopalakrishnan, R.; Meredith, M. J.; Larriba-Andaluz, C.; Hogan Jr, C. J. Brownian dynamics determination of the bipolar steady state charge distribution on spheres and non-spheres in the transition regime. Journal of Aerosol Science 2013, 63, 126-145.

(58) Wiedensohler, A.; Lütkemeier, E.; Feldpausch, M.; Helsper, C. Investigation of the bipolar charge distribution at various gas conditions. Journal of Aerosol Science 1986, 17, 413-416.

(59) Reischl, G. P.; Mäkelä, J. M.; Karch, R.; Necid, J. Bipolar charging of ultrafine particles in the size range below $10 \mathrm{~nm}$. Journal of Aerosol Science 1996, 27, 931-949.

(60) Nishida, R. T.; Boies, A. M.; Hochgreb, S. Measuring ultrafine aerosols by direct photoionization and charge capture in continuous flow. Aerosol Science and Technology 2018, 52, 546-556.

(61) Nishida, R.; Johnson, T.; Boies, A.; Hochgreb, S. Measuring aerosol active surface area by direct ultraviolet photoionization and charge capture in continuous flow. Aerosol Science and Technology 2019, 53, 1429-1440. 
For TOC Only

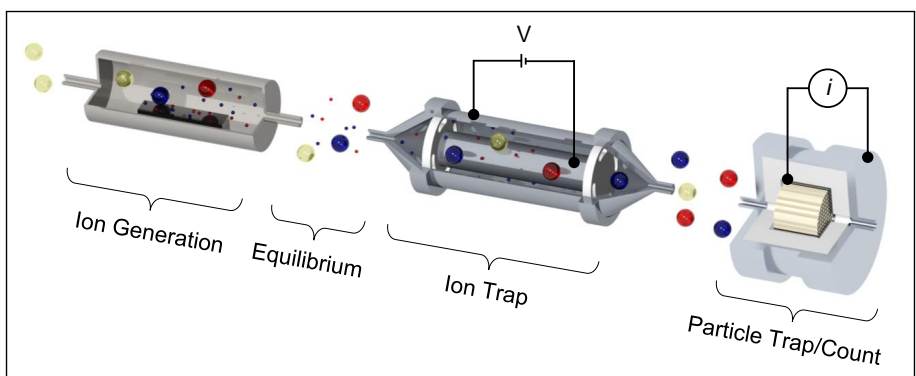

